\title{
Zinc monotherapy is effective in Wilson's disease patients with mild liver disease diagnosed in childhood: a retrospective study
}

\author{
Giusy Ranucci ${ }^{1}$, Fabiola Di Dato ${ }^{1}$, Maria Immacolata Spagnuolo ${ }^{1}$, Pietro Vajro ${ }^{2}$ and Raffaele lorio ${ }^{{ }^{*}}$
}

\begin{abstract}
Background: Wilson's disease (WD) evolves rapidly and is fatal if untreated. The treatment of WD patients with mild liver disease is not clearly defined. To address this issue, we evaluated long-term outcomes of three treatment regimens (D-penicillamine, zinc or both) in patients diagnosed in childhood.

Methods: We retrospectively evaluated efficacy, compliance and reasons for treatment discontinuation in 42 WD patients (median age at diagnosis: 6 years; median follow-up: 12 years) with mild liver disease. Treatment duration for each treatment block until a medication change or completion of follow-up was analyzed. Events of change of treatment were evaluated using Kaplan-Meier analysis.

Results: Total discontinuations due to treatment failure or adverse events were more frequent in patients receiving D-penicillamine (45\%) or combination (36\%) therapy than in patients receiving zinc (12\%) $(P=.001$ and $\mathrm{P}=.02$, respectively). Treatment failure was more frequent on D-penicillamine (28\%) and combination therapy (36\%) than on zinc (12\%); the difference was statistically significant only between zinc and combination therapy $(P=.03)$. First-line zinc monotherapy controlled WD-related liver disease in $13 / 15$ patients (87\%); the two subjects that failed on zinc were poor adherent. Zinc was effective in 3/5 (60\%) patients that failed on D-penicillamine and combination regimens. All $15 \mathrm{D}$-penicillamine responders that switched to zinc had good control of liver disease at a median follow-up of 13.1 years. Among 6 D-penicillamine non-responders that switched to zinc, 4 (67\%) responded. At follow-up completion, only 5/42 (12\%) patients failed. Adverse event-induced discontinuation was significantly more frequent in patients on $D$-penicillamine than in patients receiving zinc $(P=.03)$.
\end{abstract}

Conclusions: Zinc monotherapy is effective in controlling WD-related liver disease both as first-line and as maintenance treatment in patients with mild liver disease diagnosed in childhood.

Keywords: D-penicillamine, Zinc, Kayser-Fleischer, Copper, ATP7B, Children, Liver disease

\section{Background}

Wilson's disease (WD) is an autosomal-recessive disorder caused by mutations in the $A T P 7 B$ gene [1]. Clinical presentation can vary widely $[2,3]$, but the key features of WD are liver disease, neuropsychiatric disturbances, KayserFleischer (KF) rings, and acute episodes of hemolysis often in association with acute liver failure. WD presents with liver disease more often in children and young adults than in older adults [4]. An early diagnosis is important because

\footnotetext{
*Correspondence: riorio@unina.it

'Department of Translational Medical Science, Section of Pediatrics, University of Naples Federico II, Via Pansini 5, 80131 Naples, Italy Full list of author information is available at the end of the article
}

WD can be fatal if left untreated. Once the diagnosis has been made $[2,5]$, treatment is a lifelong necessity, and compliance must be zealously monitored [6].

The approach to treatment (drug of choice and dosage) depends on clinical presentation at diagnosis, and the severity of neurologic or hepatic disease [6]. Current treatment regimens include chelators (D-penicillamine and trientine) that promote the excretion of copper from the body, and/or zinc salts that reduce copper absorption $[2,4]$.The best therapeutic approach for each specific presentation of the disease remains controversial and there are no clear indications about how to treat WD patients with a mild liver disease [2,4]. Transplantation remains the 
treatment of choice for patients with acute liver failure due to WD as well as for treatment of patients with chronic liver failure unresponsive to medical therapy [2]. In patients with severe neurological presentation the use of zinc seems to be preferred [6].

Studies conducted on distinct groups of WD patients have demonstrated that zinc monotherapy is safe and inexpensive [7]. Zinc was successfully used as maintenance therapy in presymptomatic and pregnant patients; as firstline treatment in patients with neurological onset and in WD children with hepatic presentation [8-16]. Somewhat in contrast with these findings, Weiss et al. questioned the efficacy of zinc therapy in WD based on the retrospective observation that, in adult patients, zinc monotherapy was less effective than chelating agents in preventing the progression of liver disease and in terms of survival in the absence of liver transplantation [17].

In the attempt to provide indications regarding the treatment of WD patients with mild liver disease, and to shed light on the discordance between evidence supporting the efficacy of zinc treatment and the studies against this therapy $[17,18]$, we evaluated the long-term response to therapy and particularly the efficacy of zinc monotherapy in a series of WD patients with mild liver disease diagnosed in childhood.

\section{Patients and methods}

\section{Patients}

We retrospectively evaluated the records of all patients with WD referred to Liver Unit of our Department of Pediatrics between 1984 and 2012. Patients were eligible for the study if: 1) the diagnosis of WD was confirmed by molecular analysis or liver copper content $>250 \mu \mathrm{g} / \mathrm{g}$ dry tissue or both; 2) WD was diagnosed in childhood; and 3) data were available about clinical-laboratory features, copper metabolism and treatment (dosage and compliance) at the time of diagnosis and throughout the period of observation.

\section{Analysis of treatment}

We evaluated the clinical, laboratory and sonographic features of all patients at diagnosis of WD and throughout the observation period. Patients were considered to be affected by mild liver disease in the presence of one of the following features: (1) abnormalities of liver enzymes (aspartate aminotransferase [AST], alanine aminotransferase [ALT], $\gamma$-glutamyltransferase [GGT]) not associated to symptoms of liver disease (fatigue, anorexia, jaundice, ascites, pruritus, palmar erythema, clubbing, spider nevi) and with normal liver function tests, namely albumin, prothrombine time, bilirubin; (2) hepatomegaly with sonographic evidence of fatty liver and/or liver echostructure dishomogeneity also with normal values of liver enzymes.

We also recorded data about treatment administered in each patient during follow-up. Specifically, we collected information about each drug used, doses, efficacy, sideeffects, and reasons for medication changes. We classified the treatment regimen as: (1) D-penicillamine, (2) zinc salts, and (3) a combination of D-penicillamine and zinc. Trientine was not included because it was not commercially available in Italy at the time of the study.

We recorded the reasons for discontinuation of a drug as: treatment failure, adverse event(s), patient's request (not linked to adverse events) and maintenance regimen. Medication changes due to a shift to maintenance therapy established by the physician or upon the patient's request in the absence of adverse events were not considered in the analysis of adherence to treatment. The duration of each treatment block was defined as the period between treatment onset and either a change of medication, or completion of follow-up. Treatment blocks lasting < 6 months were not included in the analysis.

The main measure of effectiveness was the impact of therapy on the concentrations of liver enzymes (AST, ALT, GGT). Liver treatment failure was diagnosed in case of persistent hypertransaminasemia and/or in case of appearance of new clinical and/or laboratory and/or sonographic signs of disease and/or in case of the need of liver transplantation and/or death.

Patients were classified as responder or non-responder. Specifically, responders were patients whose liver enzyme values were significantly lower than baseline levels, and whose AST, ALT and GGT levels were at least lower than twice the upper limit of normal at the end of a treatment block. Patients with normal baseline levels of liver enzymes were considered responders if they maintained normal values and if other clinical, laboratory and sonographic parameters remained unchanged during follow-up. Patients were considered relapsers when efficacy parameters became deranged after a favorable response. At the end of the study, relapsers were included in the nonresponder group if inadequate dosage and other intercurrent causes of liver disease were excluded. In case of non-response to therapy, we looked for signs of poor adherence, inadequate dosage and other intercurrent causes of liver disease.

Adherence to treatment was assessed based on data about the treatment schedule (prescribed dose, number of daily doses, and adequate interval between medicine and meals), and about levels of urinary copper excretion $(<75 \mu \mathrm{g} / 24 \mathrm{~h})$, urinary zinc levels $(>2000 \mu \mathrm{g} / 24 \mathrm{~h}$ ) and serum zinc levels $(>150 \mathrm{mg} / \mathrm{dl})$ for patients treated with zinc, and urinary copper levels (values between 200 and $500 \mu \mathrm{g} / 24 \mathrm{~h}$ after a year of treatment) for patients treated with D-penicillamine.

Neurological worsening in WD patients was assessed by an oriented examination of central nervous system using clinical and radiological investigations if required. 


\section{Methods}

As recommended [2,4], D-penicillamine was used as initial and maintenance therapy for symptomatic patients, zinc salts were used as first-line treatment and maintenance for presymptomatic patients, and as maintenance therapy after a first phase with penicillamine for symptomatic patients. Starting from 1995, zinc was also used as first-line therapy in WD patients with a mild liver disease.

D-penicillamine was used as initial therapy at the dosage of $20 \mathrm{mg} / \mathrm{kg}$ daily divided in two to four doses; the maintenance dose was between 750-1500 mg daily in two or three doses. Zinc was given in sulphate form until 2004, and subsequently, when licensed in Italy, as acetate at the dosage of elemental zinc $25 \mathrm{mg}$ twice daily in children younger than 6 years; $25 \mathrm{mg}$ three times a day for children aged between 6 and 16 years of age (or weight $<57 \mathrm{~kg}$ ); and $50 \mathrm{mg}$ three times daily in patients older than 16 years of age (or weight $>57 \mathrm{~kg}$ ). Patients were instructed to take their medication at least one hour before meals or at least 2 hours after meals. The study complies with the Declaration of Helsinki.

\section{Statistical analysis}

Events of change of treatment were evaluated using Kaplan-Meier analysis. We established $\mathrm{P}$ values for this calculation using the pairwise log-rank test (Mantel-Cox). All $\mathrm{P}$ values were based on two-tailed comparisons, and those less than 0.05 were considered to indicate statistical significance. All statistical analyses were performed with GraphPad Prism version 6.00 for Mac (GraphPad Software, San Diego, CA).

\section{Results}

\section{Initial presentation of the study group}

Forty-eight consecutive patients (35 males) with a diagnosis of WD were evaluated, and 42 (30 males, median age at diagnosis: 6 years, range: $1-16$ years) were selected for treatment analysis based on our entry criteria. The $A T P 7 B$ gene was analyzed in 39 patients, and disease-causing mutations were found in 37 (17 compound heterozygotes, 13 homozygotes and 7 with a single known mutation). Nine patients were referred for family screening. All patients had signs of mild liver disease: 39 presented abnormal liver enzymes. At diagnosis, ultrasound showed hepatomegaly in $40 / 42$ patients (95\%) and steatosis in $39 / 42$ patients $(93 \%)$. Three patients had steatosis on ultrasound and normal basal liver enzymes.

In 4 patients $(9.5 \%)$, concomitant neurological/psychiatric signs (tremor, micrography, behavioral disorders) were identified only after a detailed neurological examination at the time of diagnosis, and KF rings were detected in 2 of these 4 patients. KF rings were not present in any of the remaining patients. In this subset of 4 patients brain magnetic resonance at diagnosis showed no structural abnormalities in the basal ganglia.

Baseline characteristics of 42 patients are reported in Table 1.

\section{Treatment type in the study groups}

Patients were first treated with D-penicillamine $(\mathrm{n}=27)$ or zinc $(\mathrm{n}=15)$. Of the 27 patients first treated with $\mathrm{D}$ penicillamine (median follow-up: 13.3 years; range: 6.725.2 years), 19 (70\%) shifted to zinc monotherapy. Of the 15 patients initially treated with zinc (median follow-up: 9.3 years; range: $1.6-19.8$ years), 13 (86\%) continued zinc monotherapy, 1 (7\%) returned to zinc after 3 years of combination therapy started because of relapse on initial treatment, and 1 (7\%) shifted to combination therapy. At the end of follow-up (median duration: 12 years; range: 1.625.2 years), 33 (79\%) were on zinc, 8 (19\%) on Dpenicillamine and $1(2 \%)$ on combination therapy. Basal features of two groups initially treated with D-penicillamine or zinc are reported in Table 2.

\section{Reasons for medication changes and treatment blocks}

Therapy was changed in 76 treatment blocks (30 Dpenicillamine therapy, 34 zinc therapy and 12 combination therapy). Of these, 74 treatment blocks (29 D-penicillamine therapy, 34 zinc therapy and 11 combination therapy) were suitable for analysis.

The resulting Kaplan-Meier curve for adherence to treatment, regardless of the reasons for changing medication, is shown in Figure 1A.

A change in medication due to treatment failure or adverse events was significantly more frequent in patients receiving D-penicillamine or combination therapy than in patients receiving zinc $(\mathrm{P}=.001$ and $\mathrm{P}=.02$, respectively): 4/34 zinc treatment blocks (12\%), 13/29 D-penicillamine blocks (45\%) and 4/11 combination blocks (36\%).

Change due to adverse events (Figure 1B) was significantly more frequent in patients receiving D-penicillamine and combination therapy than in patients receiving zinc $(\mathrm{P}=.03$ and $\mathrm{P}=.04$, respectively). In fact, 6/74 treatment blocks that included penicillamine (5 D-penicillamine and 1 combination) were stopped because of adverse events. A change in medication due to treatment failure (Figure 1C) was observed in 16 blocks (22\%): 8/29 D-penicillamine blocks (28\%), 4/34 zinc blocks (12\%) and 4/11 combination blocks (36\%). The difference was statistically significant between zinc and combination therapy $(\mathrm{P}=.03)$, but not between zinc and $\mathrm{D}$-penicillamine $(\mathrm{P}=.15)$. Among treatment failure blocks, non-adherence to therapy occurred in 1/8 D-penicillamine blocks (12\%), 2/4 zinc blocks (50\%) and $4 / 4$ combination blocks (100\%). In one patient on combination therapy, discontinuation was associated with both treatment failure and adverse events. There were no significant differences among treatment failure versus non-failure 
Table 1 Baseline characteristics of 42 patients with WD

\begin{tabular}{|c|c|c|c|c|c|c|c|c|c|c|c|c|}
\hline Patient & Sex & $\begin{array}{c}\text { Age at } \\
\text { diagnosis (months) }\end{array}$ & $\begin{array}{l}\text { Diagnosis by } \\
\text { familial screening }\end{array}$ & Presentation & ATP7B genotype & $\begin{array}{l}\text { AST } \\
\text { (UI/L) }\end{array}$ & $\begin{array}{l}\text { ALT } \\
(\mathrm{UI} / \mathrm{L})\end{array}$ & $\begin{array}{l}\text { GGT } \\
\text { (UI/L) }\end{array}$ & $\begin{array}{l}\text { Ceruloplasmin } \\
\text { (mg/dl) }\end{array}$ & $\begin{array}{c}\text { Basal urinary } \\
\text { copper }(\mathrm{mcg} / 24 \mathrm{~h})\end{array}$ & $\begin{array}{c}\text { Hepatic copper } \\
\text { (mcg/g dry weight) }\end{array}$ & $\begin{array}{l}\text { Liver } \\
\text { biopsy }\end{array}$ \\
\hline 1 & $\mathrm{~F}$ & 48 & Yes & Hepatic & No mutation found & 168 & 210 & 21 & 8 & 4 & 1060 & $F(I S: 1)$ \\
\hline 2 & M & 96 & No & Hepatic & No mutation found & 30 & 63 & 11 & 5 & 14 & 250 & $F(I S: 1)$ \\
\hline 3 & M & 108 & No & Hepatic & p.H1069Q/p.H1069Q & 78 & 202 & 78 & 23 & 198 & 750 & $S, F(I S: 1)$ \\
\hline 4 & $\mathrm{~F}$ & 78 & No & Hepatic & p.H1069Q/unknown & 72 & 196 & 38 & 15 & 180 & 514 & $S, F(I S: 1)$ \\
\hline 5 & M & 101 & No & Hepatic & p.H1069Q/p.H1069Q & 112 & 252 & 70 & 19 & 120 & ND & ND \\
\hline 6 & M & 60 & No & Hepatic & p.T858A/c.51 + 4A > T & 179 & 514 & 99 & 3 & 139 & 532 & S, F (IS: 2) \\
\hline 7 & $\mathrm{~F}$ & 16 & Yes & Hepatic & p.P840L/p.N1270S & 53 & 28 & 20 & 3 & 15 & ND & ND \\
\hline 8 & M & 87 & No & Hepatic & p.P840L/p.N1270S & 96 & 288 & 77 & 2 & 135 & 919 & $\begin{array}{c}\text { S, F (IS:2), } \\
\text { ACH }\end{array}$ \\
\hline 9 & $\mathrm{~F}$ & 13 & Yes & Hepatic & c.2299insG/c.2299insG & 42 & 27 & 16 & 7 & ND & ND & ND \\
\hline 10 & M & 19 & Yes & Hepatic & c.2299insG/c.2299insG & 67 & 35 & 15 & 6 & 15 & ND & ND \\
\hline 11 & M & 170 & No & Hepatic & $\begin{array}{l}\text { c.51+384_1708-953del/ } \\
\text { c.51+ 384_1708-953del }\end{array}$ & 199 & 582 & 267 & 2 & 254 & ND & $S, F(I S: 1)$ \\
\hline 12 & M & 125 & No & Mixed & p.H1069Q/p.H1207P & 35 & 106 & 62 & 18 & 300 & 300 & F (IS: 2) \\
\hline 13 & M & 74 & No & Hepatic & p.R1319X/p.R1319X & 161 & 362 & 101 & 2 & 116 & 260 & $S, F(I S: 2)$ \\
\hline 14 & $\mathrm{~F}$ & 80 & No & Hepatic & p.P840L/p.N1270S & 153 & 370 & 80 & 2 & 117 & ND & F (IS: 2) \\
\hline 15 & M & 52 & No & Hepatic & p.R1319X/unknown & 137 & 307 & 55 & 2 & 40 & 1203 & $S, F(I S: 1)$ \\
\hline 16 & M & 12 & Yes & Hepatic & $\begin{aligned} c .2447 & +5 A>G / c .2447 \\
& +5 A>G\end{aligned}$ & 55 & 57 & 20 & 11 & ND & ND & ND \\
\hline 17 & M & 73 & No & Hepatic & $\begin{aligned} c .2447 & +5 A>G / c .2447 \\
& +5 A>G\end{aligned}$ & 114 & 148 & 51 & 8 & 262 & 1056 & S, F (IS: 2) \\
\hline 18 & M & 58 & No & Hepatic & $\begin{aligned} c .2447+ & 5 A>G / c .2447 \\
+5 A & >G\end{aligned}$ & 150 & 424 & 47 & 6 & 241 & 1048 & $S(I S: 1)$ \\
\hline 19 & M & 72 & No & Hepatic & p.H1069Q/p.T1220M & 117 & 412 & 70 & 12 & 228 & ND & $S, F(I S: 2)$ \\
\hline 20 & M & 36 & Yes & Hepatic & p.H1069Q/p.T1220M & 22 & 12 & 13 & 16 & 31 & ND & ND \\
\hline 21 & M & 64 & No & Hepatic & p.D765N/unknown & 99 & 201 & 105 & 6 & 137 & 407 & ND \\
\hline 22 & M & 65 & No & Hepatic & p.H1069Q/p.H1069Q & 130 & 395 & 187 & 16 & 270 & 1129 & S, F (IS: 1) \\
\hline 23 & $\mathrm{~F}$ & 79 & No & Mixed & p.T1220M/c.51 + 4A > T & 64 & 208 & 61 & 2 & 119 & 1041 & S, F (IS: 1) \\
\hline 24 & $\mathrm{~F}$ & 29 & Yes & Hepatic & p.T1220M/c.51 + 4A > T & 54 & 50 & 21 & 2 & 22 & 1002 & S, F (IS: 1) \\
\hline 25 & $\mathrm{~F}$ & 92 & No & Hepatic & p.H1069Q/p.R1041P & 52 & 110 & 36 & 18 & 108 & 714 & S, F (IS: 1) \\
\hline 26 & M & 130 & No & Hepatic & p.T1220M/unknown & 100 & 148 & 100 & 3 & 84 & 1060 & $\mathrm{~S}, \mathrm{ACH}$ \\
\hline 27 & M & 152 & No & Hepatic & p.T1220M/unknown & 33 & 52 & 73 & 2 & 413 & 60 & $\mathrm{~S}, \mathrm{ACH}$ \\
\hline 28 & $\mathrm{~F}$ & 70 & No & Hepatic & ND & 205 & 398 & 83 & 7 & 172 & 676 & $S, F(I S: 1)$ \\
\hline 29 & M & 100 & No & Hepatic & p.S1369L/p.S1369L & 102 & 173 & 60 & 2 & 236 & ND & S, F (IS:2) \\
\hline
\end{tabular}


Table 1 Baseline characteristics of 42 patients with WD (Continued)

\begin{tabular}{|c|c|c|c|c|c|c|c|c|c|c|c|c|}
\hline 30 & M & 76 & No & Hepatic & p.G591D/p.R969Q & 146 & 502 & 119 & 7 & 780 & 761 & S \\
\hline 31 & M & 69 & No & Hepatic & $\begin{array}{c}\text { c.2304-2305 insC/c.2304- } \\
2305 \mathrm{insC}\end{array}$ & 117 & 276 & 103 & 2 & 595 & 977 & S \\
\hline 32 & M & 42 & No & Hepatic & p.V1262F/p.V1297N & 117 & 262 & 41 & 2 & 14 & ND & ND \\
\hline 33 & M & 73 & No & Hepatic & p.H1069Q/p.G711E & 169 & 480 & 227 & 18 & 150 & 620 & S, F (IS: 1) \\
\hline 34 & M & 192 & No & Mixed & p.H1069Q/p.N1270S & 27 & 23 & 32 & 6 & 165 & 970 & S, F (IS: 2) \\
\hline 35 & M & 75 & No & Hepatic & c.1782delT/c.3182G > A & 185 & 398 & 70 & 4 & 180 & 296 & S, F (IS: 2) \\
\hline 36 & M & 29 & Yes & Hepatic & c.1782delT/c.3182G > A & 69 & 64 & 16 & 2 & 16 & 1230 & S \\
\hline 37 & $\mathrm{~F}$ & 63 & No & Hepatic & p.A1003T/p.A1003T & 80 & 147 & 45 & 38 & 66 & 785 & $\mathrm{~S}, \mathrm{ACH}$ \\
\hline 38 & M & 99 & No & Hepatic & ND & 79 & 181 & 89 & 4 & 91 & 780 & $S, F(I S$ 1) \\
\hline 39 & $\mathrm{~F}$ & 72 & No & Hepatic & p.1899F/p.N1270S & 66 & 215 & 67 & 8 & 157 & 1449 & S, F (IS: 1) \\
\hline 40 & M & 56 & No & Hepatic & c.2304dupC/unknown & 188 & 483 & 102 & 2 & 138 & 1660 & S, F (IS: 2) \\
\hline 41 & M & 39 & Yes & Hepatic & c.2304dupC/unknown & 51 & 37 & 11 & 3 & 25 & 904 & $S, F(I S: 1)$ \\
\hline 42 & $\mathrm{~F}$ & 84 & No & Mixed & ND & 156 & 187 & 191 & 3 & 145 & 600 & $S, F(I S: 1)$ \\
\hline
\end{tabular}


Table 2 Basal clinical and laboratory features of patients initially treated with D-penicillamine or zinc

\begin{tabular}{|c|c|c|c|}
\hline & D-Penicillamine & Zinc & $P$ values \\
\hline Patients (N) & 27 (21 males) & 15 (9 males) & \\
\hline Median age at diagnosis (months) & 75 (range 39-192) & 42 (range 12-101) & $<0.001^{*}$ \\
\hline Median ALT at diagnosis (UI/L) & 251 (range 23-582) & 110 (range 12-502) & $0.022^{*}$ \\
\hline Median AST at diagnosis (UI/L) & 114 (range 27-205) & 67 (range 22-168) & 0.059 (NS) \\
\hline Median GGT at diagnosis (UI/L) & 72 (range $11-267$ ) & 21 (range 13-119) & $0.019^{*}$ \\
\hline Basal urinary copper ( $\mu \mathrm{g} / 24 \mathrm{~h})$ & 150 (range 14-413) & 31 (range 4-780) & 0.91 (NS) \\
\hline Median liver copper content ( $\mu \mathrm{g} / \mathrm{g}$ dry tissue) & 780 (range 60-1660) & 989 (range 407-1230) & 0.423 (NS) \\
\hline
\end{tabular}

*P values less than 0.05 were considered statistically significant; NS: not significant.

blocks in relation to gender $(\mathrm{P}=.35)$ and pre-treatment liver enzyme levels (ALT, $\mathrm{P}=.50$; AST, $\mathrm{P}=.21$; GGT, $\mathrm{P}=.15$ ) (Figure $2 \mathrm{~A}, \mathrm{~B}$ and $\mathrm{C}$ ) or fibrosis grade at diagnosis $(\mathrm{P}=.65)$. Zinc was effective in $3 / 5$ patients that failed on D-penicillamine and/or combination regimen.

In $12 / 74$ treatment blocks (16\%), we recorded a transient flare-up of liver enzymes that did not lead to treatment failure in 8/34 zinc blocks (24\%), after a median follow-up of 78 months (range: 36-96 months), and in 4/29 Dpenicillamine treatment blocks (14\%), after a median follow-up of 54 months (range: 42-72 months). Seven of the 8 relapser zinc blocks and 3/4 relapser D-penicillamine blocks were related to an inadequate dosage, and liver enzymes returned to normal value after adjusting dosage. Among relapser blocks, we identified non-adherence to therapy in $1 / 8$ zinc blocks and in 1/4 D-penicillamine blocks.

\section{Response of patients to therapy}

At the end of follow-up, treatment failure was recorded in 5/42 (12\%) patients and 3 of these patients were poor compliers. However all patients remained symptom-free and none had worsening of liver and/or neurological disease, died or needed liver transplantation. Twenty (74\%) of the 27 patients initially treated with D-penicillamine responded to therapy (within a median of 23 months; range 6-36 months). Seven of the 27 patients (26\%) treated with D-penicillamine were non-responders. In this group, ALT levels decreased during treatment from a median baseline value of $398 \mathrm{IU} / \mathrm{L}(173-582 \mathrm{IU} / \mathrm{L})$ to $165 \mathrm{IU} / \mathrm{L}$ (91-377 IU/L) at the end of follow-up. One non-responder patient was treated for only 4 months and was then shifted successfully to zinc; thus, this block was not included in the discontinuation analysis.

Only one non-responder to D-penicillamine therapy had urinary copper excretion levels compatible with poor adherence to treatment. There were no significant differences in urinary copper excretion at 3, 6, 12 and 24 months between responders and non-responders to D-penicillamine (Figure 3). Six of the non-responders to D-penicillamine switched to zinc therapy: 4 (67\%) responded to the new treatment within a median of 12 months (range 6-

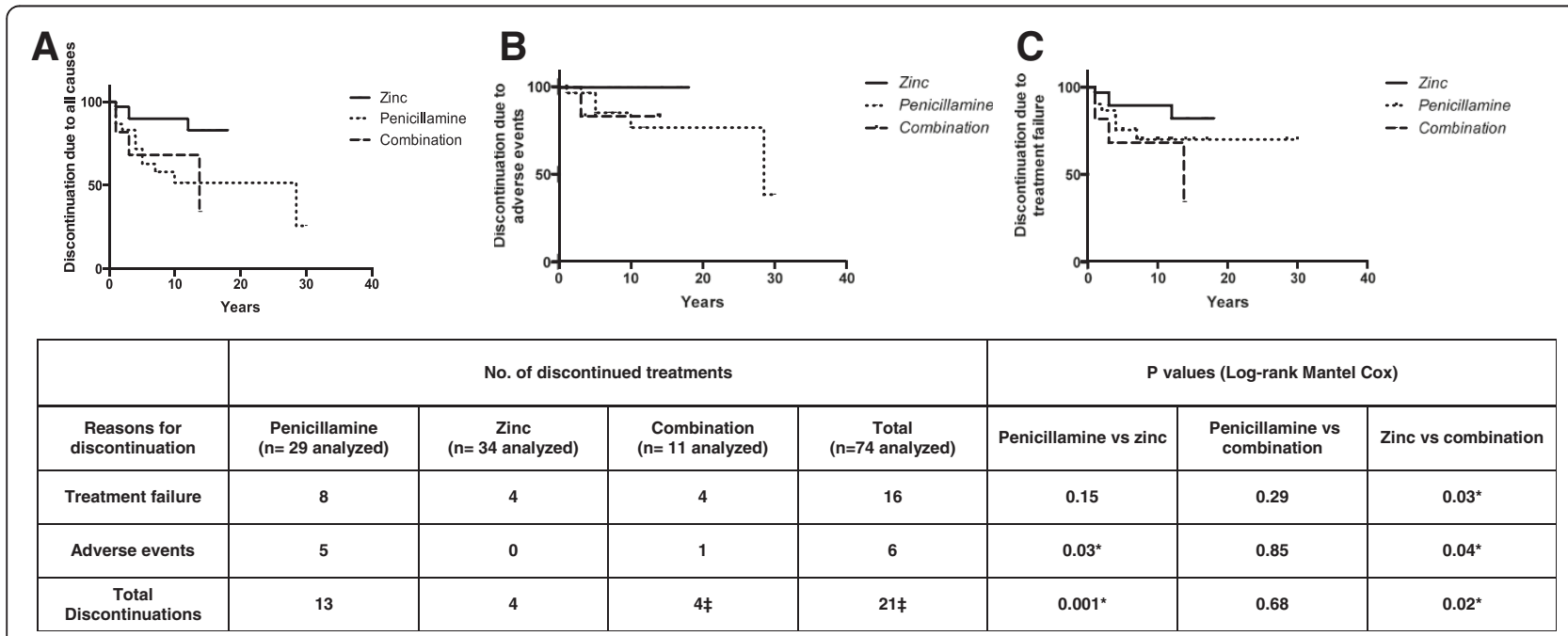

Figure 1 Change of treatment due to any cause (A), adverse events (B), treatment failure (C), analyzed by the Kaplan-Meier estimation. *P values less than 0.05 were considered statistically significant. fIn one patient on combination therapy, discontinuation was associated with both treatment failure and adverse events. 


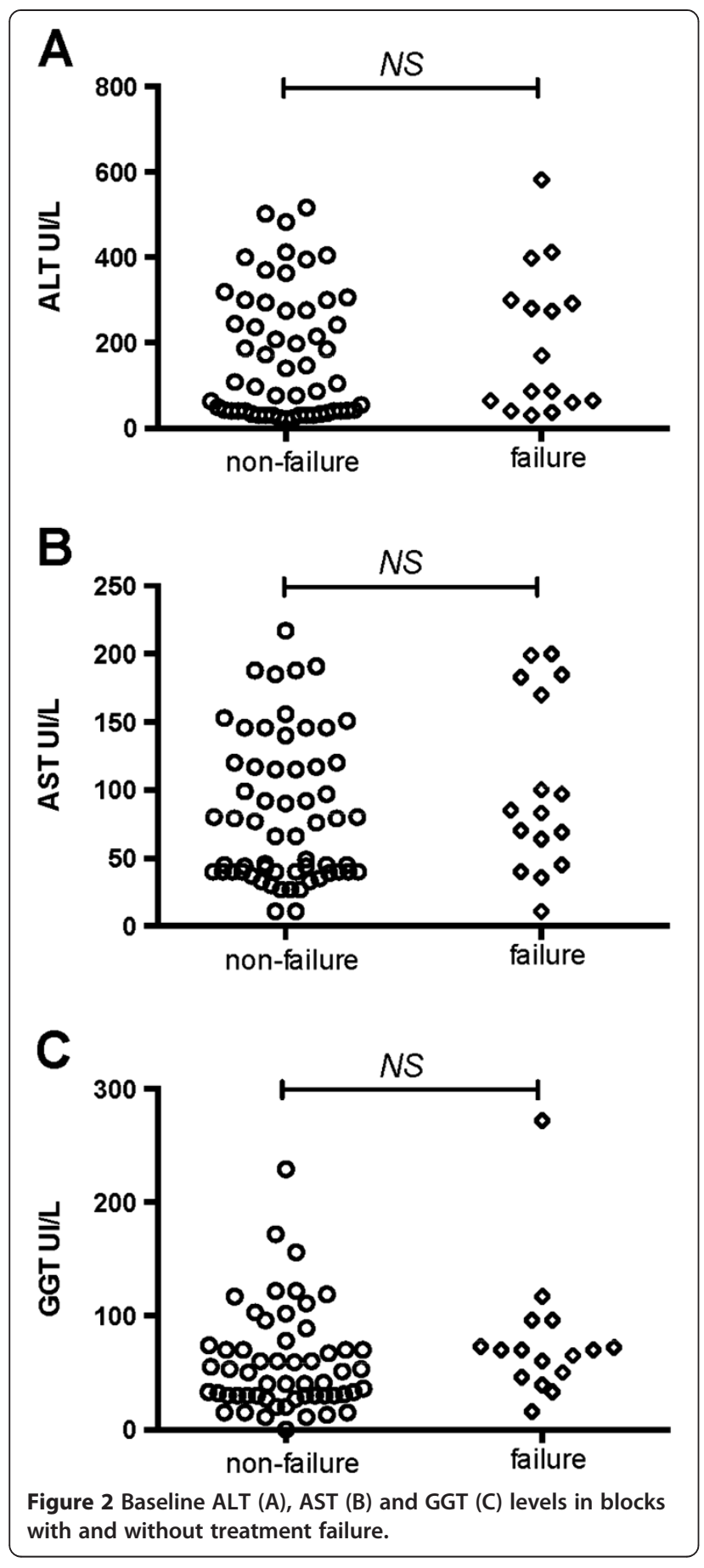

36 months), whereas hypertransaminasemia persisted in the other two. Among the 20 long-term responders to Dpenicillamine, 6 (33\%) continued therapy with this drug and obtained good control of hepatic disease (median ALT at the end of follow-up: $36 \mathrm{IU} / \mathrm{L}$; range 12-77 IU/L), whereas 14 patients (69\%) switched to zinc monotherapy (9 as maintenance therapy and 5 due to D-penicillaminerelated adverse events). None of the long-term responders to D-penicillamine who switched to zinc showed hepatic worsening after a median follow-up of 13.1 years (range: 0.7 to 20.2 years) and all achieved optimal control of the disease (ALT upon completion of follow-up was $33 \mathrm{IU} / \mathrm{L}$, range: $11-57 \mathrm{IU} / \mathrm{L})$. Table 3 shows the data about AST, ALT and GGT in patients on D-penicillamine during the follow-up, grouped by treatment response.

Of the 15 patients initially treated with zinc, 13 (87\%) responded (within a median of 12 months; range: 324 months) and the median ALT at the end of follow-up was $49 \mathrm{IU} / \mathrm{L}$ (range: 18-79 IU/L). The two non-responders to zinc complied poorly with treatment, as witnessed by inadequate levels of serum and urinary zinc and/or copper excretion. Both non-responders switched to combination therapy without normalization of aminotransferase and one patient asked to return to zinc therapy. In these two patients, ALT levels on zinc therapy increased from a median baseline of $57 \mathrm{IU} / \mathrm{L}$ (range: 50-64 IU/L) to a median of $172 \mathrm{IU} / \mathrm{L}$ (range: 132-212 IU/L) at the end of follow-up. No patient showed during the entire period of observation signs of neurological and/or psychiatric worsening. Table 4 shows the profile of AST, ALT and GGT levels in the responders and non-responders to zinc therapy.

\section{Adverse events under therapy}

Adverse events occurred in 28/42 patients: 10 on Dpenicillamine, 13 on zinc and 5 on combination therapy. Six of the 42 patients, 5 on D-penicillamine and 1 on combination regimen, changed therapy due to severe adverse events. The following D-penicillamine-related side effects were recorded: maculo-papular rash (8 cases), elastosis perforans serpiginosa (1 case), skin pigmentation (1 case), alopecia (1 case), altered taste ( 2 cases), proteinuria (3 cases), leucopenia and/or thrombocytopenia (3 cases). Neurologic worsening was observed in 3 patients (7\%), all under D-penicillamine: tremor in 2 children and worsening of neurological/psychiatric symptoms in a patient with hepatic and neurologic features at onset. No patient on a zinc regime needed to change treatment; the only adverse effect associated with zinc was mild gastric pain and mild elevation of serum lipase and amylase without the symptoms of pancreatitis.

\section{Discussion}

Considering the rarity of WD and the lack of clear indications on how to treat WD patients with mild liver disease $[2,4]$, the importance of the present study lies in the fact that it evaluated zinc monotherapy in a large and homogeneous group of patients with mild liver disease due to WD, diagnosed in childhood (median age: 6 years) and monitored for a long period (median duration: 12 years). The features of our series are remarkably different from those of other pediatric reports, which in most cases included WD children with either acute or chronic symptomatic liver disease [11,17-19]. In fact, the WD patients 


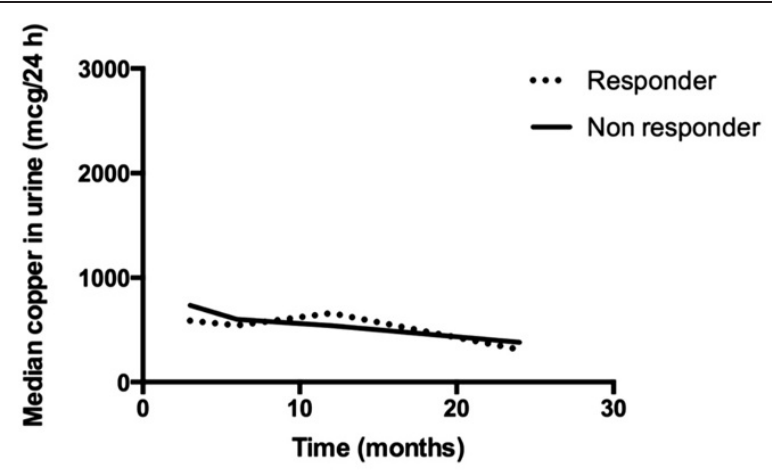

\begin{tabular}{|c|c|c|c|c|}
\hline & & & $\begin{array}{c}\text { Median mcg/24h } \\
\text { (range) }\end{array}$ & $\begin{array}{c}\mathbf{P} \\
\text { value }\end{array}$ \\
\hline \multirow{8}{*}{ URINARY COPPER LEVELS (mcg/24h) } & \multirow{2}{*}{3 months } & responder & $558(75-2520)$ & \multirow{2}{*}{.69} \\
\hline & & non-responder & $736(627-840)$ & \\
\hline & \multirow{2}{*}{6 months } & responder & $543(209-2527)$ & \multirow{2}{*}{.58} \\
\hline & & non-responder & $601(290-1035)$ & \\
\hline & \multirow{2}{*}{12 months } & responder & $662(228-2382)$ & \multirow{2}{*}{.51} \\
\hline & & non-responder & $540(264-610)$ & \\
\hline & \multirow{2}{*}{24 months } & responder & $310(101-1914)$ & \multirow{2}{*}{.52} \\
\hline & & non-responder & $380(318-442)$ & \\
\hline
\end{tabular}

Figure 3 Course of urinary copper levels of patients on D-penicillamine treatment, grouped by treatment response.

evaluated in the present study were affected by mild liver disease. This reflects the fact that in Italy aminotransferase serum levels are measured during all routine checkups and before surgical procedures. Regarding the retrospective nature of the study, given the rarity of WD, it is virtually impossible to carry out prospective randomized controlled trials in the short-mid term to determine the optimal therapeutic schedules. In the analyzed setting, zinc monotherapy was effective both as first-line monotherapy and as maintenance treatment after initial decoppering with the chelator D-penicillamine. Changes of therapy were significantly more frequent in patients receiving $\mathrm{D}$-penicillamine or combination therapy than patients receiving zinc monotherapy. Similarly, treatment failure and adverse events occurred more frequently on D-penicillamine. Interestingly, zinc failure was more frequently related to non-adherence to therapy than D-penicillamine failure.

In our study, the rate of normalization of liver enzymes was much higher in patients who started on zinc than in those who started on D-penicillamine. However, we cannot conclude that zinc monotherapy is more effective than Dpenicillamine given the heterogeneity of the groups initially treated with D-penicillamine or zinc in terms of age at diagnosis and baseline ALT and GGT levels. Therefore the main message of our study is that both D-penicillamine and zinc are effective in controlling liver involvement in WD patients with mild liver disease diagnosed in childhood. It cannot be excluded that decoppering treatment when used as first drug might favor in some way the beneficial effect of zinc monotherapy in patients switching to this regimen.
In line with previous reports $[7,8,14,19]$, the present study indicates that clinically relevant adverse events, including neurologic worsening, in some cases requiring treatment modifications, are more common on Dpenicillamine than on zinc. Contrary to the group on Dpenicillamine, none of our patients on zinc needed to change therapy because of side effects.

At variance with our data and those of others [8-16], the efficacy of zinc treatment for WD was recently questioned $[17,18]$. Several factors may be evoked to explain this discordance. Most of the patients evaluated by Weiss et al. started therapy in the adult age, when obviously the liver expression of WD is more severe. In the subset of patients classified as non-responders, they did not include patients who died or who underwent liver transplantation (10 under chelator versus 4 on zinc and 1 on combination therapy). Another important difference is that zinc was given as second-line therapy in their patients with liver disease. Thus, 11/14 patients that had hepatic failure on zinc after a median of 2.7 years (range: $0.67-18.34$ ) of treatment had already received D-penicillamine for a median of 12.31 years (range: 0.27-33.59), and the outcome of these patients on chelator therapy was not reported. Therefore, the clinical status of these patients at the time of starting zinc therapy was not well defined. Moreover, although Weiss et al. reported that liver enzymes normalized in zinc non-responders after reintroduction of a chelating agent (rescue therapy), they did not provide information about rescue therapy. In contrast to these results, liver disease 
Table 3 Course of liver enzymes in patients initially treated with D-penicillamine, grouped by treatment response

\begin{tabular}{|c|c|c|c|c|}
\hline & & & $\begin{array}{c}\text { Median } \\
\text { UI/L (range) }\end{array}$ & $P$ value \\
\hline \multirow{10}{*}{ ALT (UI/L) } & \multirow{2}{*}{ Baseline } & Responder & $201(23-514)$ & \multirow{2}{*}{.19} \\
\hline & & Non-responder & $398(173-582)$ & \\
\hline & \multirow{2}{*}{6 months } & Responder & $122(32-576)$ & \multirow{2}{*}{.26} \\
\hline & & Non-responder & $236(165-279)$ & \\
\hline & \multirow{2}{*}{12 months } & Responder & $60(20-178)$ & \multirow{2}{*}{$\leq .001$} \\
\hline & & Non-responder & $91(83-166)$ & \\
\hline & \multirow{2}{*}{24 months } & Responder & $46(14-76)$ & \multirow{2}{*}{$\leq .001$} \\
\hline & & Non-responder & $205(65-245)$ & \\
\hline & \multirow{2}{*}{$>36$ months } & Responder & $36(12-77)$ & \multirow{2}{*}{$\leq .001$} \\
\hline & & Non-responder & 165 (91-377) & \\
\hline \multirow{10}{*}{ AST(UI/L) } & \multirow{2}{*}{ Baseline } & Responder & $114(27-227)$ & \multirow{2}{*}{.24} \\
\hline & & Non-responder & 117 (72-205) & \\
\hline & \multirow{2}{*}{6 months } & Responder & $60(26-198)$ & \multirow{2}{*}{.23} \\
\hline & & Non-responder & $94(89-115)$ & \\
\hline & \multirow{2}{*}{12 months } & Responder & $43(22-74)$ & \multirow{2}{*}{.18} \\
\hline & & Non-responder & $60(47-60)$ & \\
\hline & \multirow{2}{*}{24 months } & Responder & $38(24-51)$ & \multirow{2}{*}{$\leq .001$} \\
\hline & & Non-responder & $100(85-114)$ & \\
\hline & \multirow{2}{*}{$>36$ months } & Responder & $32(20-61)$ & \multirow{2}{*}{.004} \\
\hline & & Non-responder & $66(40-76)$ & \\
\hline \multirow{10}{*}{ GGT(UI/L) } & \multirow{2}{*}{ Baseline } & Responder & $68(11-227)$ & \multirow{2}{*}{.54} \\
\hline & & Non-responder & $74(48-267)$ & \\
\hline & \multirow{2}{*}{6 months } & Responder & 39 (14-119) & \multirow{2}{*}{.64} \\
\hline & & Non-responder & $59(49-65)$ & \\
\hline & \multirow{2}{*}{12 months } & Responder & $27(13-57)$ & \multirow{2}{*}{.19} \\
\hline & & Non-responder & $42(36-48)$ & \\
\hline & \multirow{2}{*}{24 months } & Responder & $24(12-44)$ & \multirow{2}{*}{.29} \\
\hline & & Non-responder & $31(31-32)$ & \\
\hline & 36 menthe & Responder & $17(12-40)$ & \\
\hline & & Non-responder & $31(25-41)$ & .29 \\
\hline
\end{tabular}

did not worsen in any of our long-term responders to Dpenicillamine after switching to zinc monotherapy.

Again, we applied very stringent criteria to identify responders to therapy. In the Weiss' study, the ranges of ALT and GGT in the responders at the end of the study were very wide (10-226 UI/L and 10-178 UI/L, respectively) and included values more than twice the upper limit of normal. In addition, while we evaluated zinc monotherapy for a median follow-up of 9.3 years, Weiss et al. did not report details about patients treated with zinc alone, apart from stating that the median duration of zinc therapy was 2.7 years in non-responders to zinc.

A major problem with WD treatment is that patients must comply strictly to therapy because low compliance or treatment discontinuation is associated with a high
Table 4 Course of liver enzyme levels in patients initially treated with zinc, grouped by treatment response

\begin{tabular}{|c|c|c|c|c|}
\hline & & & $\begin{array}{c}\text { Median } \\
\text { UI/L (range) }\end{array}$ & $P$ value \\
\hline \multirow{10}{*}{ ALT (UI/L) } & \multirow{2}{*}{ Baseline } & Responder & $201(12-502)$ & \multirow{2}{*}{.30} \\
\hline & & Non-responder & $57(50-64)$ & \\
\hline & \multirow{2}{*}{6 months } & Responder & $72(24-233)$ & \multirow{2}{*}{.93} \\
\hline & & Non-responder & $82(64-101)$ & \\
\hline & \multirow{2}{*}{12 months } & Responder & $51(26-94)$ & \multirow{2}{*}{$\leq .001$} \\
\hline & & Non-responder & $172(132-212)$ & \\
\hline & \multirow{2}{*}{24 months } & Responder & $41(23-80)$ & \multirow{2}{*}{ - } \\
\hline & & Non-responder & - & \\
\hline & \multirow{2}{*}{$>36$ months } & Responder & $49(18-79)$ & \\
\hline & & Non-responder & - & \\
\hline \multirow{10}{*}{ AST (UI/L) } & \multirow{2}{*}{ Baseline } & Responder & $67(22-168)$ & \multirow{2}{*}{.42} \\
\hline & & Non-responder & 59 (49-69) & \\
\hline & \multirow{2}{*}{6 months } & Responder & $46(34-83)$ & \multirow{2}{*}{.81} \\
\hline & & Non-responder & $56(48-64)$ & \\
\hline & \multirow{2}{*}{12 months } & Responder & $44(35-66)$ & \multirow{2}{*}{$\leq .001$} \\
\hline & & Non-responder & $156(92-221)$ & \\
\hline & \multirow{2}{*}{24 months } & Responder & $40(26-74)$ & \multirow{2}{*}{ - } \\
\hline & & Non-responder & - & \\
\hline & \multirow{2}{*}{$>36$ months } & Responder & $36(19-61)$ & \multirow{2}{*}{ - } \\
\hline & & Non-responder & - & \\
\hline \multirow{10}{*}{ GGT (UI/L) } & \multirow{2}{*}{ Baseline } & Responder & $36(13-119)$ & \multirow{2}{*}{.34} \\
\hline & & Non-responder & $18(16-21)$ & \\
\hline & \multirow{2}{*}{6 months } & Responder & $30(13-49)$ & \multirow{2}{*}{.35} \\
\hline & & Non-responder & $40(22-59)$ & \\
\hline & \multirow{2}{*}{12 months } & Responder & $22(11-55)$ & \multirow{2}{*}{$\leq .001$} \\
\hline & & Non-responder & $86(45-127)$ & \\
\hline & \multirow{2}{*}{24 months } & Responder & $18(13-38)$ & \\
\hline & & Non-responder & - & \\
\hline & \multirow{2}{*}{$>36$ months } & Responder & $16(13-43)$ & \\
\hline & & Non-responder & - & \\
\hline
\end{tabular}

risk of hepatic decompensation that may even require liver transplantation [2]. Treatment compliance was not assessed by Weiss et al. They reported a lack of significant differences in serum and urinary zinc values between their responders and non-responders to zinc therapy; however, they did not report details about urinary copper levels. Consequently, they may have misjudged treatment adherence. It is noteworthy that the patients of Linn et al. that worsened under zinc therapy were later discovered not to have adhered to treatment based on their urinary copper levels [18]. In our study, the evaluation of urinary copper levels revealed an irregular intake of the drug in one of two non-responders to zinc who had appropriate serum and urinary zinc levels. Another important finding of our study is that urinary copper excretion does not represent a 
reliable efficacy parameter on penicillamine therapy, because some responders persistently maintain urinary copper level higher than $500 \mathrm{mcg} / \mathrm{day}$. On the other hand, urinary copper excretion remains useful for evaluating the adherence to treatment in nonresponders to penicillamine and guiding the shift to zinc monotherapy in patients initially treated with penicillamine $[2,4]$. It is important to note that treatment failure was more frequent in our patients on combination therapy than in patients on other regimens, and that it was invariably linked to poor compliance. Given this result and the fact the efficacy of combination therapy is not yet well proven, the latter strategy should probably be avoided.

\section{Conclusions}

In conclusion, our study addresses the challenge of how to treat WD patients with mild liver disease, diagnosed in childhood. In fact, we demonstrate that zinc monotherapy is effective in controlling WD-related liver disease both as first-line and as maintenance treatment in patients with mild liver disease. Its efficacy was evaluated in a large homogeneous cohort of WD patients diagnosed in childhood and followed for a long period. This study raises the possibility of treating, when indicated, WD patients with an effective and safe drug as zinc.

\section{Availability of supporting data}

The data sets supporting the results of this article are included within the article and its additional files.

\section{Abbreviations \\ WD: Wilson's disease; ATP7B: ATPase, Cu++ transporting beta polypeptide; KF: Kayser-Fleisher: ALT: Alanine aminotransferase; AST: Aspartate aminotransferase; $\gamma$-GT: $\gamma$-glutamyltransferase.}

\section{Competing interests}

The authors declare that they have no financial or non-financial competing interests.

\section{Authors' contributions \\ Dr. GR conceptualized and designed the study, carried out analyses and interpretation of data, drafted the initial manuscript, and approved the final manuscript as submitted. Dr. FDD conceptualized and designed the study, carried out analyses and interpretation of data, drafted the initial manuscript, and approved the final manuscript as submitted. Dr. MIS designed the study, collected, analyzed, and interpreted the data and was responsible for drafting and revising the manuscript. Prof. PV designed the study, collected and interpreted the data, revised the manuscript, and approved the final version of the manuscript. Prof. RI conceptualized and designed the study, coordinated and supervised data collection and interpretation, drafted the initial manuscript, and approved the final manuscript as submitted. All authors read and approved the final version of the article, including the authorship list.}

\section{Acknowledgment}

The authors thank Jean Ann Gilder (Scientific Communication srl, Naples, Italy) who provided writing assistance and Dr. Georgios Loudianos for performing the molecular analysis of all the patients included in this study.

\section{Author details}

'Department of Translational Medical Science, Section of Pediatrics, University of Naples Federico II, Via Pansini 5, 80131 Naples, Italy. ${ }^{2}$ Chair of
Pediatrics, Department of Medicine and Science, University of Salerno, 84081 Fisciano (Salerno), Italy.

Received: 15 December 2013 Accepted: 20 March 2014

Published: 25 March 2014

\section{References}

1. Ala A, Walker AP, Ashkan K, Dooley JS, Schilsky ML: Wilson's disease. Lancet 2007, 369:397-408.

2. Roberts EA, Schilsky ML: Diagnosis and treatment of Wilson disease: an update. Hepatology 2008, 47:2089-111.

3. Nicastro E, Loudianos G, Zancan L, D'Antiga L, Maggiore G, Marcellini M, Barbera C, Marazzi MG, Francavilla R, Pastore M, Vajro P, D'Ambrosi M, Vegnente A, Ranucci G, lorio R: Genotype-phenotype correlation in Italian children with Wilson's disease. J Hepatol 2009, 50:555-61.

4. European Association for the Study of the Liver: EASL clinical practice guidelines: Wilson's disease. J Hepatol 2012, 56:671-85.

5. Nicastro E, Ranucci G, Vajro P, Vegnente A, lorio R: Re-evaluation of the diagnostic criteria for Wilson disease in children with mild liver disease. Hepatology 2010, 52:1948-56

6. Brewer GJ, Askari FK: Wilson's disease: clinical management and therapy. J Hepatol 2005, 42(Suppl 1):S13-S21.

7. Wiggelinkhuizen M, Tilanus ME, Bollen CW, Houwen RH: Systematic review: clinical efficacy of chelator agents and zinc in the initial treatment of Wilson disease. Aliment Pharmacol Ther 2009, 29:947-58.

8. Czlonkowska A, Gajda J, Rodo M: Effects of long-term treatment in Wilson's disease with D-penicillamine and zinc sulphate. J Neurol 1996, 243:269-273.

9. Hoogenraad TU: Zinc treatment of Wilson's disease. J Lab Clin Med 1998, 132:240-241.

10. Brewer GJ, Dick RD, Yuzbasiyan-Gurkan V, Johnson V, Wang Y: Treatment of Wilson's disease with zinc: XIII. Therapy with zinc in presymptomatic patients from the time of diagnosis. J Lab Clin Med 1994, 123:849-58.

11. Brewer GJ, Dick RD, Johnson VD, Fink JK, Kluin KJ, Daniels S: Treatment of Wilson's disease with zinc XVI: treatment during the pediatric years. J Lab Clin Med 2001, 137:191-8.

12. Brewer GJ, Johnson VD, Dick RD, Hedera P, Fink JK, Kluin KJ: Treatment of Wilson's disease with zinc. XVII: treatment during pregnancy. Hepatology 2000, 31:364-370.

13. Hoogenraad TU, Koevoet R, de Ruyter Korver EG: Oral zinc sulphate as long-term treatment in Wilson's disease (hepatolenticular degeneration). Eur Neurol 1979, 18:205-211.

14. Marcellini M, Di Ciommo V, Callea F, Devito R, Comparcola D, Sartorelli MR, Carelli G, Nobili V: Treatment of Wilson's disease with zinc from the time of diagnosis in pediatric patients: a single-hospital, 10-year follow-up study. J Lab Clin Med 2005, 145:139-143.

15. Iorio R, D'Ambrosi M, Marcellini M, Barbera C, Maggiore G, Zancan L, Giacchino R, Vajro P, Marazzi MG, Francavilla R, Michielutti F, Resti M, Frediani T, Pastore M, Mazzarella G, Fusco G, Cirillo F, Vegnente A, Hepatology Committee of Italian Society of Paediatric Gastroenterology Hepatology and Nutrition: Serum transaminases in children with Wilson's disease. J Pediatr Gastroenterol Nutr 2004, 39:331-6.

16. Mizuochi T, Kimura A, Shimizu N, Nishiura H, Matsushita M, Yoshino M: Zinc monotherapy from time of diagnosis for young pediatric patients with presymptomatic Wilson disease. J Pediatr Gastroenterol Nutr 2011, 53:365-367.

17. Weiss KH, Gotthardt DN, Klemm D, Merle U, Ferenci-Foerster D, Schaefer M, Ferenci P, Stremmel W: Zinc monotherapy is not as effective as chelating agents in treatment of Wilson disease. Gastroenterology 2011, 140:1189-1198.

18. Linn FH, Houwen RH, van Hatten J, van der Kleij S, van Erpecum KJ: Longterm exclusive zinc monotherapy in symptomatic Wilson disease: experience in 17 patients. Hepatology 2009, 50:1442-1452.

19. Merle U, Schaefer M, Ferenci P, Stremmel W: Clinical presentation, diagnosis and long-term outcome of Wilson's disease: a cohort study. Gut 2007, 56:115-120.

doi:10.1186/1750-1172-9-41

Cite this article as: Ranucci et al:: Zinc monotherapy is effective in Wilson's disease patients with mild liver disease diagnosed in childhood: a retrospective study. Orphanet Journal of Rare Diseases 2014 9:41. 